84

Content list available at: https://openbiomarkerjournal.com

RESEARCH ARTICLE

\title{
Serum Vascular Endothelial Growth Factor in Patients with Hepatocellular Carcinoma and its Validity as a Tumor Biomarker
}

\author{
Noha A. Sadik ${ }^{1, *}$, Nagwa R. Ahmed ${ }^{1}$, Moataz F. Mohamed ${ }^{1}$ and Omar A. Ashoush ${ }^{1}$ \\ ${ }^{1}$ Internal Medicine Department, Faculty of Medicine, Kasr Al Ainy Hospital, Cairo University, Cairo, Egypt
}

\begin{abstract}
:
Background:

Hepatocellular Carcinoma (HCC) is one of the most common cancers associated with deaths worldwide and the presence of valid biomarkers for early diagnosis in high-risk patients can ameliorate the outcome of HCC. Vascular Endothelial Growth Factor (VEGF) has been found to play an essential role in the process of HCC growth and progression.

Objectives:

Therefore, we evaluated the serum VEGF levels in patients with HCC and liver cirrhosis and estimated its significant value for differentiating HCC patients from liver cirrhosis patients.

Material and methods:

Eighty-one subjects were enrolled in the study, 30 patients had HCC, 31 patients had liver cirrhosis and 20 were healthy control subjects. VEGF and AFP were measured using ELIZA. Abdominal ultrasound and triphasic abdominal computed tomography were performed in all subjects. Receiver Operating Characteristics curve analysis was performed for serum VEGF to determine its validity as a tumor biomarker.

Results:

The median levels of the serum VEGF were highly expressed in the HCC group (418 pg/ml) and the liver cirrhosis group (308 pg/ml) with no significant difference $(P=0.767)$; however both groups showed a significant increase compared to the control group $(0.8 \mathrm{pg} / \mathrm{ml}, P<0.000)$. Serum VEGF showed high sensitivity $(100 \%)$ and high specificity $(100 \%)$ in differentiating HCC patients from controls with a cut-off value of $\geq 64.2$ $\mathrm{pg} / \mathrm{ml}$, although it showed low sensitivity $(29.2 \%)$ and specificity $(85.7 \%)$ for differentiating HCC patients from liver cirrhosis patients.

\section{Conclusion:}

VEGF can be used as a reliable biomarker for differentiating HCC patients from healthy subjects but it can't be used as a reliable biomarker for differentiating HCC patients from high-risk patients as liver cirrhosis. The elevated serum VEGF levels in HCC and liver cirrhosis patients can elucidate the crucial role of angiogenesis in HCC and liver cirrhosis.
\end{abstract}

Keywords: Hepatocellular carcinoma, Liver cirrhosis, VEGF, AFP, Angiogenesis, Biomarker.

\begin{tabular}{|l|l|l|lr} 
Article History & Received: October 08, 2019 & Revised: November 23, 2019 & Accepted: December 13, 2019 \\
\hline
\end{tabular}

\section{INTRODUCTION AND BACKGROUND}

Hepatocellular Carcinoma (HCC) is the main cause of primary liver cancer [1] and the fifth common cause of cancers worldwide [2] and the second main cause of cancer-associated deaths with increasing prevalence [3]. Population based-studies showed that most patients suffering from HCC died of this

\footnotetext{
* Address correspondence to this author at Internal Medicine Department, Faculty of Medicine, Kasr Al Ainy Hospital, Cairo University, Dyar City Middle Hill El Mokattam, Cairo, Egypt, Postal code: 11571; Tel: +201278444526 E-mail: noha_adly@yahoo.com
}

disease [2] where patients who develop symptoms of HCC have survival rate between $0 \%-10 \%$; [4] but with early diagnosis, the 5-year survival rate is greater than $50 \%$ [5]. The relationship between HCC and cirrhosis has been documented suggesting that Hepatitis B Virus (HBV) and Hepatitis C Virus $(\mathrm{HCV})$ are the most prevalent causes of HCC $[6,7]$. HCC is usually diagnosed at intermediate and late stages due to its long incubation period and insidious onset [8]. Therefore early diagnosis in high-risk population as in chronic hepatitis-related liver cirrhosis by a reliable biomarker can improve the outcome 
of HCC [9]. AFP is still used for diagnosis and screening of HCC [10], yet it has low sensitivity as in early stages and with small tumors [11] or has high false-positive results as with chronic hepatitis and liver cirrhosis [12]. Measurement of AFP with other liver biomarkers can increase its sensitivity and specificity $[13,14]$.

Angiogenesis is a dynamic process of hypoxia and growth factors where it leads to the formation of new vessels. Liver angiogenesis is either physiological as in liver regeneration or pathological as in chronic liver diseases, HCC, and metastatic liver cancer [15]. Vascular Endothelial Growth Factor (VEGF) is the main leading force for the physiological and pathological angiogenesis and is found to be highly expressed in HCC [16]. VEGF enhances tumor angiogenesis by various means as accelerating the endothelial cells migration, invasion, survival enhancing the vascular permeability through attachment to specific endothelial cells receptors [17]. Various studies assessed the crucial role of VEGF in the development, growth, metastasis, angiogenesis in HCC patients [18, 19]. Also, researchers demonstrated the crucial role of angiogenesis in the process of liver fibrosis [20, 21]. Therefore we assessed the serum levels of VEGF in HCC patients and patients with HCV related liver cirrhosis and evaluated its validity as a reliable biomarker for differentiating HCC patients from liver cirrhosis patients.

\section{MATERIAL AND METHODS}

\subsection{Subjects}

We performed this case-control study from April 2017 to June 2018 on 81 subjects divided into 3 groups. Group (1) included 30 patients having HCC, group (2) included 31 patients having Liver Cirrhosis (LC) secondary to $\mathrm{HCV}$ infection (HCV related LC) from preliminary 80 liver cirrhosis patients selected from the inpatients of Kasr Al Ainy University Hospital, Internal Medicine Department and group (3) included 20 healthy age-matched control subjects.

\subsubsection{Inclusion and Exclusion Criteria}

In our study, we included adult patients known to have HCC diagnosed clinically and radiologically by triphasic abdominal CT as recommended by the European Association for the Study of the Liver (EASL) guidelines [22] and patients known to have liver cirrhosis due to $\mathrm{HCV}$ irrespective of age and sex. We excluded patients with liver cirrhosis secondary to $\mathrm{HBV}$ infection, autoimmune, metabolic liver diseases and on hepatotoxic drugs. Fig. (1) shows a flow chart for the inclusion and exclusion criteria of the study.

\subsubsection{Ethical Aspects}

Research protocol was approved by the medical ethics committee of Kasr Al Ainy Hospital Medical School, Faculty of Medicine, Cairo University. All the participants provided informed consent for the research protocol. The research protocol follows the ethical guidelines of the 1975 declaration of Helsinki.

\subsubsection{Laboratory Tests}

Full history and clinical examination were performed in all subjects. Only serum blood sample was taken for measurement of complete blood picture, Alanine Transaminase (ALT), Aspartate Transaminase (AST), Gamma-Glutamyl Transferase (GGT), Prothrombin Time (PT), Prothrombin Concentration (PC), International Normalized Ratio (INR), urea, creatinine, hepatitis B surface antigen, hepatitis C virus antibody, AFP and VEGF. Abdominal ultrasound and triphasic abdominal Computed Tomography (CT) were performed in the studied groups. Serum VEGF level was measured by the human Quantikine $^{\circledR}$ ELISA kits (R\&D Systems, Minneapolis, MN, USA) according to the manufacturer's instructions.

The Quantikine ${ }^{\circledR}$ Human VEGF Immunoassay is a 4.5 hour solid-phase ELISA ready to calculate human VEGF165 levels in serum. It includes Sf 21-expressed recombinant human VEGF165 and antibodies raised against the recombinant protein. Results gained for naturally occurring human VEGF and recombinant human VEGF121 exhibited linear curves that were, as the standard curves, obtained using the Quantikine ${ }^{\circledR}$ kit standards. These conclusions indicate that we can use this kit to set the relative mass values for natural human VEGF.

\subsubsection{Sample Collection and Storage}

The samples taken were left for clotting 30 minutes before centrifugation for 15 minutes at $1000 \mathrm{x}$ g. Serum and assay removed immediately and stored at $\leq-20^{\circ} \mathrm{C}$. We also avoided repeated freezing and melting series.

\subsection{Principle of the Method}

The human VEGF kit is a solid phase sandwich Enzyme Linked-Immuno-Sorbent Assay (ELISA). The samples together with the standards, controls and unknowns were poured in the wells of microtiter strips together with a polyclonal human VEGF antibody and left to incubate where the human VEGF bound to the immobilized antibody after washing and biotinylated monoclonal antibody specific for human VEGF was added and left for second incubation where the biotinylated monoclonal antibody bound with the already captured immobilized antibody in the first incubation. The second wash was given again to remove the excess antibody formed, then Streptavidin-Peroxidase (enzyme) was added which bound to the biotinylated antibody to form the fourmember sandwich. After a third incubation and wash to remove the entire unbound enzyme, a substrate was added where color was generated and its strength was observed to be positively correlated to the human VEGF concentrates present in the original sample. When color generation stopped we calculated its strength.

\subsubsection{Statistical Analysis}

Data was analyzed through the Statistical Package of Social Science Software program, version 23 (IBM SPSS Statistics for Windows, Version 23.0. Armonk, NY: IBM Corp.). Data were presented using the median and inter-quartile range for quantitative variables and frequency and percentage for qualitative ones. Normality was checked through the 
Kolmogorov-Smirnov test to choose the right inferential statistical test. A comparison between groups for quantitative variables was carried out using Kruskal Wallis tests followed by the Mann Whitney test for pair-wise comparisons while the comparison of qualitative variables was performed through Chi-square test. $P$ values less than 0.05 were considered statistically significant. Figures (Box plots) were used to illustrate some information. Receiver Operating Characteristics (ROC) curve analysis was carried out for VEGF and AFP. Youden's J statistic was calculated for each cut-off point as follows [sensitivity + specificity -1 ], the selected cut-off point was the one that achieved the higher Youden's $\mathrm{J}$ value considering the higher sensitivity and specificity.

\section{RESULTS}

Our HCC group included 25 (83.3\%) men and 5 (16.7\%) women with mean age $(58.6 \pm 8.1$ years). The HCV LC group included $16(51.6 \%)$ men and $15(48.4 \%)$ women with mean age (54.3 \pm 6.3 years), and the control group included $10(50 \%)$ men and $10(50 \%)$ women with mean age (48.9 12.9 years). History of gastrointestinal bleeding was found in 21 (67.7\%) HCC patients and $22(73.3 \%)$ HCV related LC patients. By examination, we detected jaundice in $12(40 \%)$ HCC patients and in $7(22.6 \%) \mathrm{HCV}$ related LC patients, lower limb edema in $15(50 \%) \mathrm{HCC}$ patients and in $19(61.3 \%) \mathrm{HCV}$ related LC patients and hepatic encephalopathy in $17(56.7 \%)$ HCC patients and in $16(51.6 \%) \mathrm{HCV}$ related LC patients. By abdominal ultrasound, we detected ascites in 22 (73.3\%) patients in the HCC group and in $21(67.7 \%)$ patients in the HCV LC group. We also found portal vein thrombosis in 10 (33.3\%) patients in the HCC group and in $12(38.7 \%)$ patients in the HCV liver cirrhosis group. By computed tomography, intraabdominal lymphadenopathy was detected in 5 (16.7\%) patients in the HCC group and also single hepatic focal lesion was detected in 9 patients, 2 lesions in 6 patients, 3 lesions in 3 patients and 4 lesions in 3 patients.

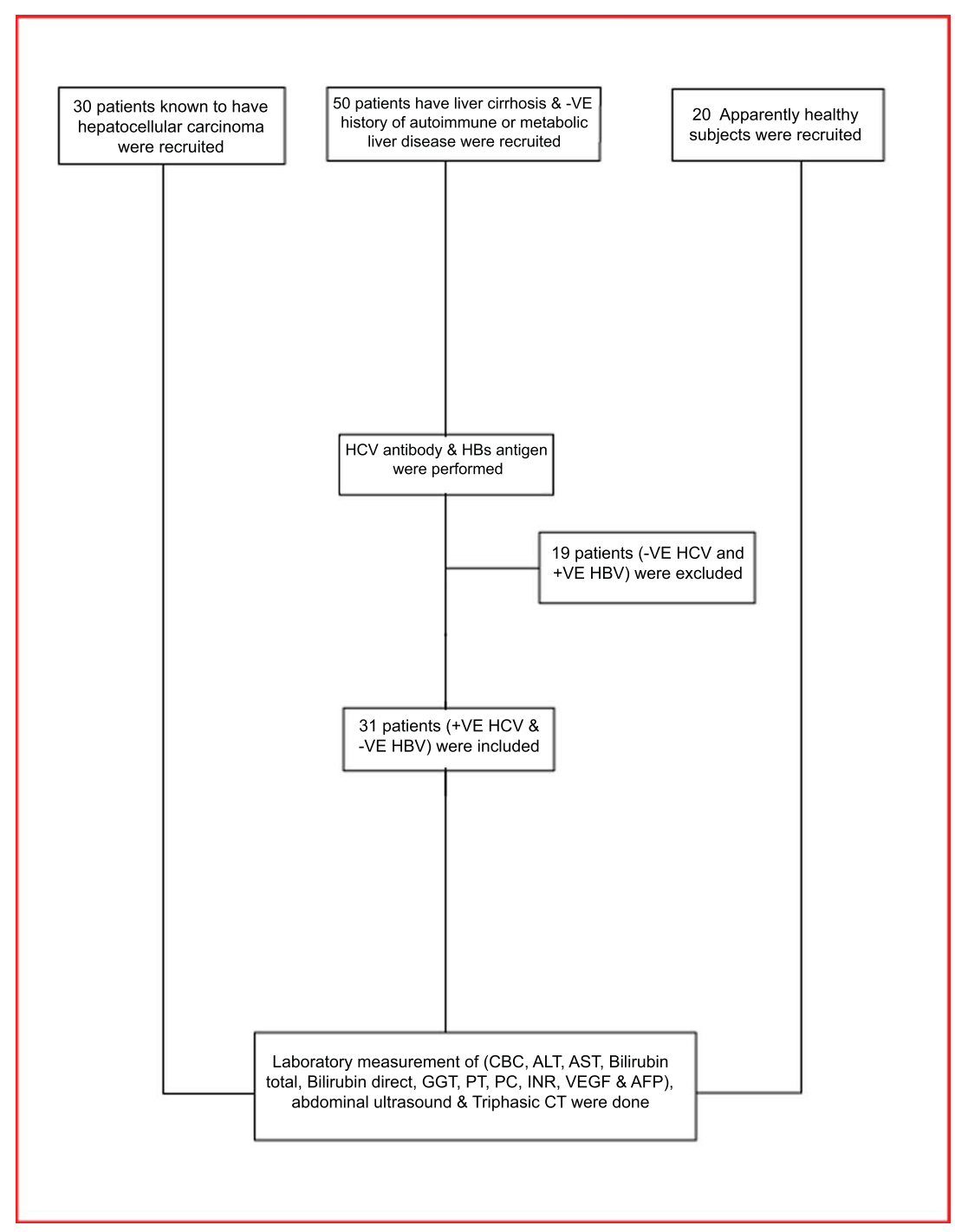

Fig. (1). Flow chart shows the study inclusion and exclusion criteria. 
Table 1 shows the demographic and laboratory data of the studied groups. There was a statistically significant difference in age $(P=0.006)$ with significant (male) predominance in the HCC group $(P=0.014)$ (Table 1).

In our study, the serum levels of VEGF were significantly different by comparing the three groups $(\mathrm{P}<0.000)$. By comparing serum VEGF levels between every 2 groups, we found no significant difference in the median serum VEGF levels in HCC group (418 pg/ml) compared to HCV LC group with median $(308 \mathrm{pg} / \mathrm{ml}, P=0.767)$ but there was a significant increase in their median serum VEGF levels compared to the control group $(0.8 \mathrm{pg} / \mathrm{ml}, P<0.000)$ (Table 2, Fig. 2). For serum AFP, there were no significant differences in the median serum levels of AFP in patients with HCC $(9.4 \mathrm{ng} / \mathrm{ml})$ compared to patients with HCV LC $(9.8 \mathrm{ng} / \mathrm{ml}, P=0.609)$ and control group (27 ng/ml, $P=0.057$ ) (Table 2).

To detect the relationship between serum VEGF expression and portal vein thrombosis, we found a significant increase in the median serum levels of VEGF $(1686 \mathrm{pg} / \mathrm{ml})$ in patients having portal vein thrombosis in the HCC group (10 patients) compared to HCC patients (20 patients) who did not have portal vein thrombosis $(242 \mathrm{pg} / \mathrm{ml}, P=0.008)$ but this comparison was not significant in the HCV LC group (Table 3).

Table 1. Demographic and laboratory data of the studied groups.

\begin{tabular}{|c|c|c|c|c|}
\hline- & $\begin{array}{c}\text { HCC } \\
(n=30)\end{array}$ & $\begin{array}{c}\text { HCV } \\
(n=31)\end{array}$ & $\begin{array}{c}\text { Control } \\
(n=20)\end{array}$ & $P$ value \\
\hline Age (years) & $58.6 \pm 8.1$ & $54.3 \pm 6.3$ & $48.9 \pm 12.9$ & $0.006^{*}$ \\
\hline Sex & - & - & - & - \\
\hline Male & $25(83.3 \%)$ & $16(51.6 \%)$ & $10(50 \%)$ & $0.014 *$ \\
\hline Female & $5(16.7 \%)$ & $15(48.4 \%)$ & $10(50 \%)$ & \\
\hline $\mathbf{H b}(\mathrm{gm} / \mathrm{dl})$ & $9.7 \pm 1.9$ & $9.4 \pm 2.3$ & $12.2 \pm 1.4$ & $0.000 *$ \\
\hline TLC $\mathrm{mm}^{3}$ & $10.4 \pm 5.9$ & $8.9 \pm 6.4$ & $7.2 \pm 2.3$ & 0.247 \\
\hline PLTs $\mu \mathrm{L}$ & $142.8 \pm 82.6$ & $110.1 \pm 57.8$ & $261 \pm 78.8$ & $0.000 *$ \\
\hline ALT (U/L) & $110.2 \pm 187.7$ & $58.5 \pm 29.3$ & $45.7 \pm 7.1$ & 0.051 \\
\hline AST (U/L) & $246 \pm 47.2$ & $82.7 \pm 39.6$ & $60.93 \pm 13.83$ & $0.012 *$ \\
\hline Albumin $(\mathrm{gm} / \mathrm{dl})$ & $2.14 \pm 0.58$ & $2.26 \pm 0.48$ & $3.66 \pm 0.31$ & $<0.001 *$ \\
\hline Bil Total (mg/dl) & $3.4 \pm 3.5$ & $3.7 \pm 5.3$ & $0.8 \pm 0.2$ & $0.004 *$ \\
\hline Bil Direct $(\mathrm{mg} / \mathrm{dl})$ & $2.33 \pm 2.74$ & $1.74 \pm 2.60$ & $0.41 \pm 0.19$ & $0.003 *$ \\
\hline PT (sec) & $18.26 \pm 3.76$ & $18.79 \pm 3.90$ & $12.26 \pm 0.29$ & $<0.001^{*}$ \\
\hline PC \% & $50.42 \pm 14.37$ & $52.13 \pm 13.41$ & $99.24 \pm 1.03$ & $<0.001^{*}$ \\
\hline INR & $1.80 \pm 0.71$ & $1.67 \pm 0.44$ & $1.04 \pm 0.11$ & $<0.001^{*}$ \\
\hline
\end{tabular}

Values are expressed as mean $\pm \mathrm{SD},{ }^{*} P<0.05$ is significant, HB, haemoglobin, TLC, Total Leucocytic Count, PLTs, Platelets, ALT, Alanine Transaminase, AST, Aspartate Transaminase, Bil, Bilirubin, PT, Prothrombine Time, PC, Prothrombine Concentration, INR, International Normalized Ratio.

Table 2. Serum levels of VEGF and AFP in the studied groups.

\begin{tabular}{|c|c|c|c|c|c|c|c|}
\hline- & HCC $(\mathbf{1})(\mathbf{n}=\mathbf{3 0})$ & HCV (2) $(\mathbf{n}=\mathbf{3 1})$ & Control $(\mathbf{3})(\mathbf{n}=\mathbf{2 0})$ & $\boldsymbol{P}$ value & $\mathbf{1 * 2}$ & $\mathbf{2 * 3}$ & $\mathbf{1 * 3}$ \\
\hline VEGF $(\mathrm{pg} / \mathrm{ml})$ Range & $3420-127$ & $0.8-3760$ & $0.1-1.3$ & & & & \\
\hline Median (IQR) & $418(198-1480)$ & $308(160.5-2416)$ & $0.8(0.4-1)$ & $0.000^{*}$ & 0.767 & $0.000^{*}$ & $0.000^{*}$ \\
\hline AFP $(\mathrm{ng} / \mathrm{ml})$ Range & $0.6-953$ & $1.2-311$ & $14-45$ & & & & \\
\hline Median (IQR) & $9.4(2.8-26.2)$ & $9.8(2.7-255)$ & $27(21-33)$ & 0.165 & 0.609 & 0.484 & 0.057 \\
\hline
\end{tabular}

IQR, Inter-Quartile Range, ${ }^{*} P<0.05$ is significant, AFP, Alpha-Feto Protein, VEGF, Vascular Endothelial Growth Factor, $1 * 2$, comparison between HCC group and HCV LC group, $1 * 2$, comparison between HCV LC group and control group, $1 * 3$, comparison between HCC group and control group.

Table 3. Comparison between the serum levels of VEGF in patients with and without portal vein thrombosis

\begin{tabular}{|c|c|c|}
\hline- & Portal Vein Thrombosis in HCV LC Group & P value \\
\hline- & Yes (12) & - \\
\hline VEGF $(\mathrm{pg} / \mathrm{ml})$ & - & - \\
\hline Range & $0.8-3112$ & $93-3760$ \\
\hline Mean $\pm S D$ & $1654 \pm 1385.4$ & $726.1 \pm 1010$ \\
\hline Median $(I Q R)$ & $2416(131-2821)$ & $304(222-720)$ \\
\hline- & Portal Vein Thrombosis in HCC Group & 0.482 \\
\hline- & Yes (10) & P value (20) \\
\hline
\end{tabular}


(Table 3) contd.....

(Table 3) contd.....
\begin{tabular}{|c|c|c|c|}
\hline- & Portal Vein Thrombosis in HCV LC Group & P value \\
\hline- & - & - & No (19) \\
\hline VEGF $(\mathrm{pg} / \mathrm{ml})$ & $221-3420$ & - \\
\hline Range & $1834.1 \pm 1322.1$ & -2100 \\
\hline Mean $\pm S D$ & $1686(664-3166)$ & $536.2 \pm 604.4$ \\
\hline Median $(I Q R)$ & & - \\
\hline
\end{tabular}

IQR, Inter-Quartile Range, ${ }^{*} P<0.05$ is significant.

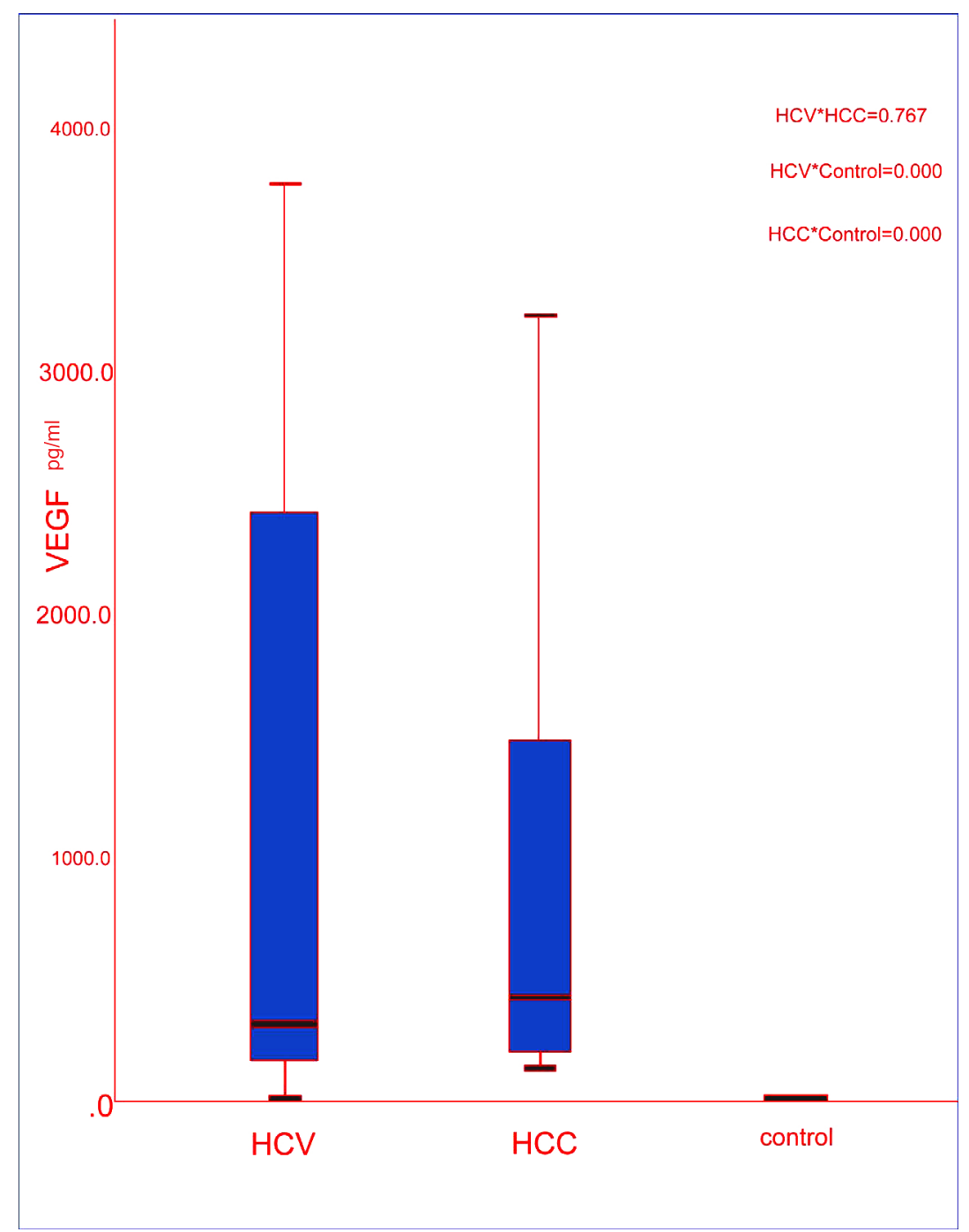

Fig. (2). Box plot shows the comparison of serum VEGF levels among our studied groups.

To detect the relationship between VEGF with other parameters, we found that the serum levels of VEGF and AFP were strongly correlated significantly both in the HCC group ( $\mathrm{r}$ $=0.868, P=0.000)$ and HCV LC group $(\mathrm{r}=0.685, P=0.000)$. There was no significant correlation between the VEGF and the number of hepatic focal lesions $(\mathrm{r}=1.09, P=0.637)$. Moreover, there were no significant correlations between VEGF and (age, Haemglobin, PLTs, WBCs, albumin, AST, direct bilirubin, INR) in the HCC group or HCV LC group (Table 4).

By using ROC curve analysis, we found that the cut-off value $\geq 64.2 \mathrm{pg} / \mathrm{ml}$ of serum VEGF showed $100 \%$ sensitivity and $100 \%$ specificity with $\mathrm{AUC}=1.00$ to differentiate $\mathrm{HCC}$ patients from control group but we found low sensitivity $(23.8 \%)$ and high specificity (100\%) for AFP to differentiate HCC patients from control group (Table 5, Fig. 3).

Also, we found that the cut-off value $\geq 47.2 \mathrm{pg} / \mathrm{ml}$ yielded $91.7 \%$ sensitivity and $100 \%$ specificity with $\mathrm{AUC}=0.968$ for serum VEGF to differentiate HCV LC patients from the control group. In addition, low sensitivity $41.7 \%$ and specificity $100 \%$ for serum AFP were found in differentiating HCV LC patients from control with a cut off value of $\geq 47.5 \mathrm{ng} / \mathrm{ml}$ (Table 6, Fig. 4)

Due to the nonsignificant difference in serum VEGF levels between HCC patients and HCV LC patients, we found low 
sensitivity of $29.2 \%$ and specificity of $85.7 \%$ with a cut-off value $\geq 2281 \mathrm{pg} / \mathrm{ml}$ for VEGF to differentiate HCC patients from HCV LC patients and we found low sensitivity for AFP for differentiating $\mathrm{HCC}$ patients from patients with liver cirrhosis (41.7\%) with AUC of 0.545 and specificity of $76.2 \%$ with a cut-off value $\geq 38.1 \mathrm{ng} / \mathrm{ml}$ (Table 7, Fig. (5).

\section{DISCUSSION}

Most studies reported an increased expression of serum VEGF levels in patients with $\mathrm{HCC}$ and its reliability for diagnosis of HCC in high-risk patients with liver cirrhosis together with AFP $[16,23,24]$. The increased expression of VEGF in HCC patients was due to the increased tissue transcript of the VEGF level in the tumor [25], where VEGF enhanced the angiogenesis and increased the vascular endothelial cells, leading to cancer formation [26]. Therefore, this study evaluated its value in patients with HCC and liver cirrhosis and further analysed its significance in differentiating patients with $\mathrm{HCC}$ from high-risk patients as $\mathrm{HCV}$ related liver cirrhosis. Interestingly, we found contradictory results. We did not find a significant difference in the median serum levels of VEGF between HCC patients and HCV LC patients but we found significant elevations in their median serum VEGF levels in comparison to the control group and these findings are in agreement just with two studies [27, 28].

Giatromanolaki et al., also reported significantly increased levels of VEGF in patients with cirrhosis than control and they postulated a crucial role of VEGF in hepatic fibrosis progress through increased fibroblast stimulation [29]. Raluca et al., reported the high expression of VEGF in the liver tissue of chronic hepatitis and liver cirrhosis patients, and they assumed that this elevation is related to malignant transformation of liver cells. They further suggested that early use of anti-VEGF treatments might decrease the risk of neoplastic transformation [30]. Interestingly, Deli et al., assessed VEGF in the hepatic tissue and serum in patients with liver cirrhosis and HCC and found a significant elevation in VEGF in the surrounding liver cirrhosis tissue than the HCC tissue which correlated with the serum VEGF levels [31].

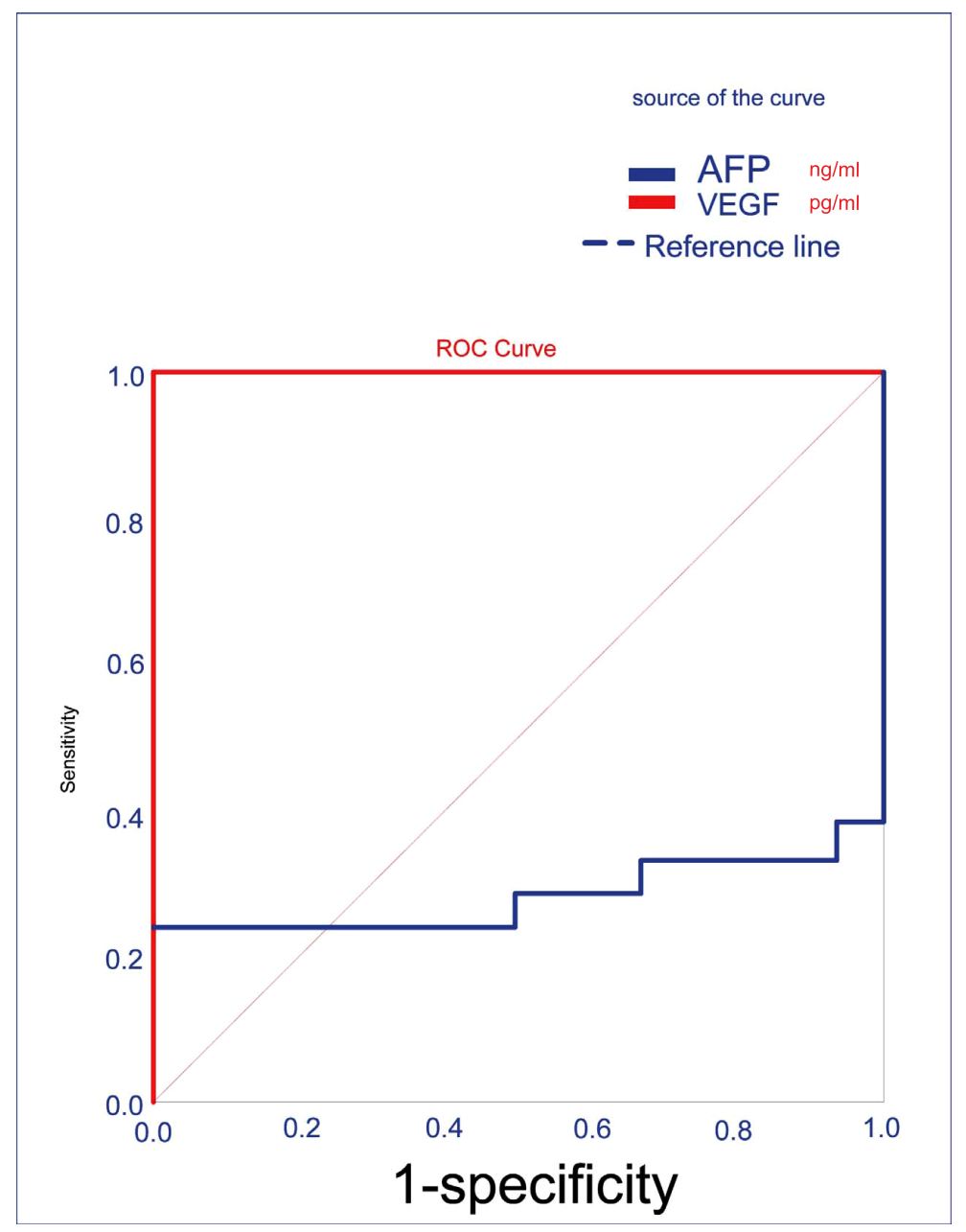

Fig. (3). ROC curve analysis to explore the discriminated ability of VEGF and AFP to differentiate HCC patients from controls. 


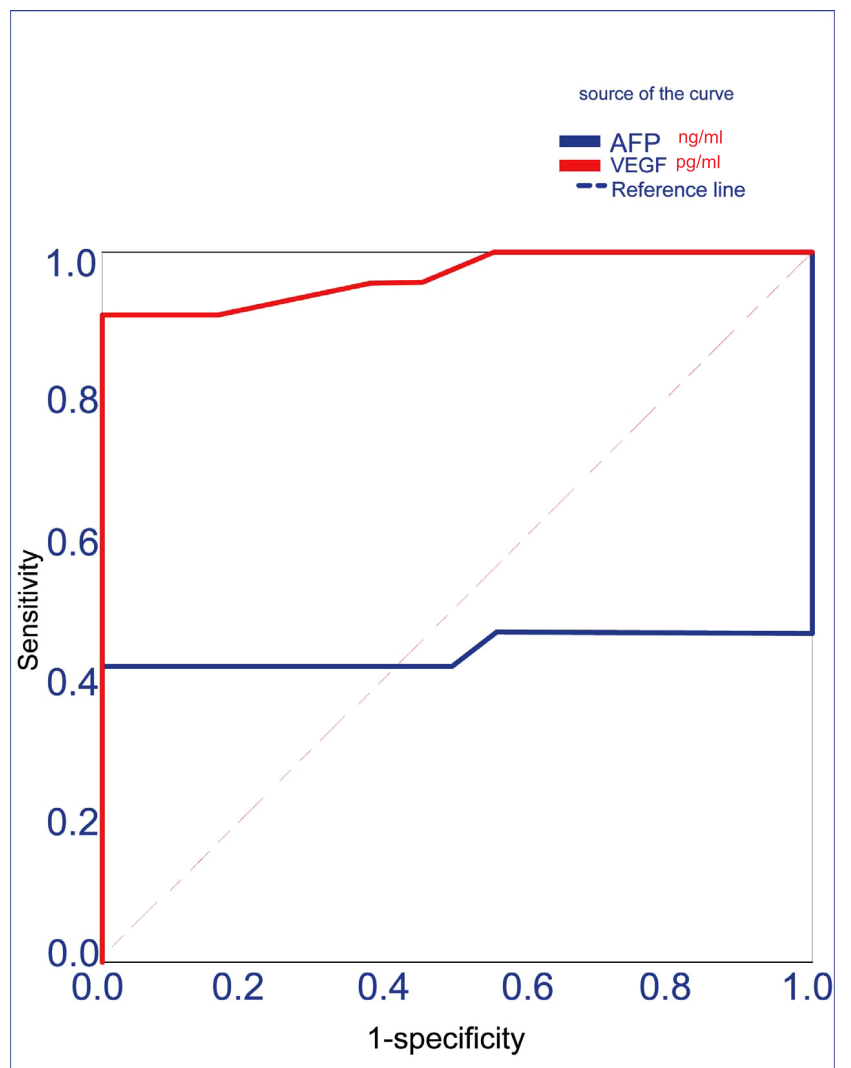

Fig. (4). ROC curve analysis to explore the discriminated ability of VEGF and AFP to differentiate HCV LC patients from controls.

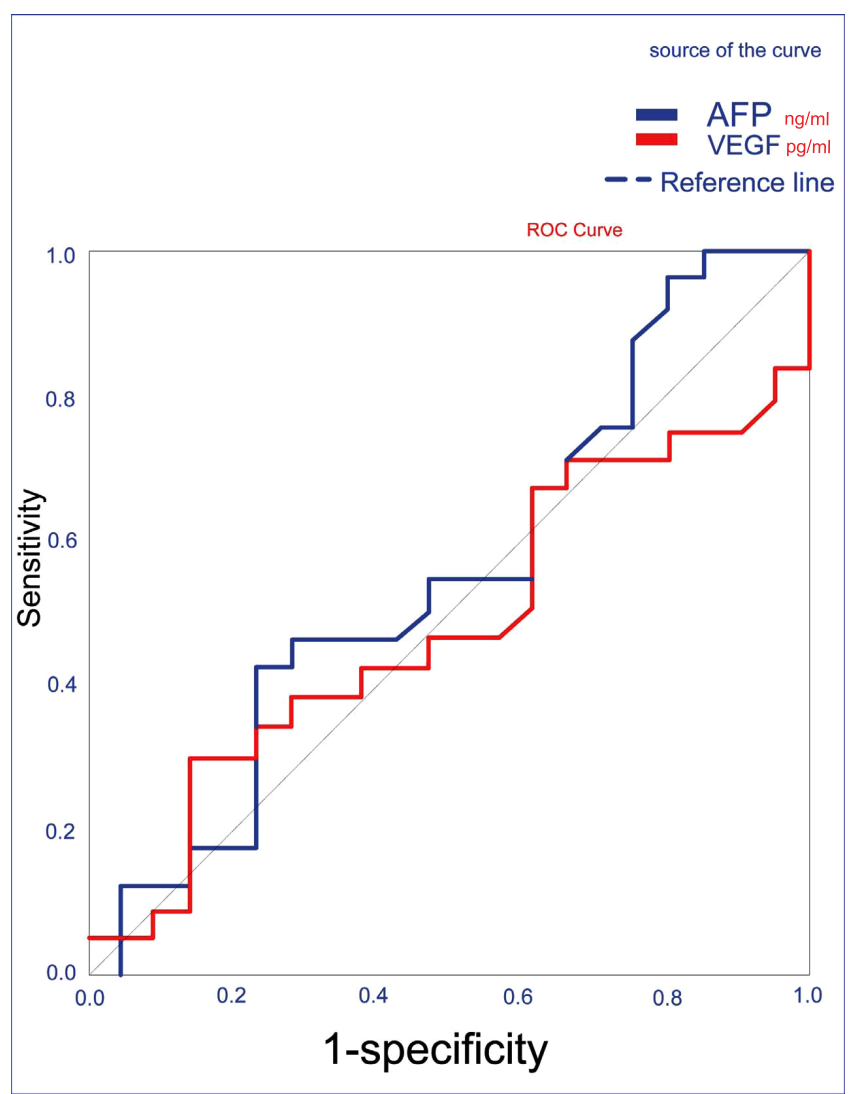

Fig. (5). ROC curve analysis to explore the discriminated ability of VEGF and AFP to differentiate HCC patients from HCV LC patients. 
Table 4. Correlation of VEGF \& AFP with different parameters in patients groups.

\begin{tabular}{|c|c|c|c|c|c|c|c|c|}
\hline \multirow{3}{*}{$\begin{array}{l}- \\
- \\
-\end{array}$} & \multicolumn{4}{|c|}{ HCV Group } & \multicolumn{4}{|c|}{ HCC Group } \\
\hline & \multicolumn{2}{|c|}{ VEGF } & \multicolumn{2}{|c|}{ AFP } & \multicolumn{2}{|c|}{ VEGF } & \multicolumn{2}{|c|}{ AFP } \\
\hline & $\mathbf{r}$ & $\mathbf{P}$ & $\mathbf{r}$ & $\mathbf{P}$ & $\mathbf{r}$ & $\mathbf{P}$ & $\mathbf{r}$ & $\mathbf{P}$ \\
\hline AFP & 0.685 & $0.000 *$ & - & - & 0.868 & $0.000^{*}$ & - & - \\
\hline Age & -0.076 & 0.724 & -0.194 & 0.365 & -0.098 & 0.674 & -0.042 & 0.858 \\
\hline $\mathbf{H b}$ & -0.113 & 0.599 & -0.146 & 0.496 & 0.120 & 0.605 & 0.279 & 0.221 \\
\hline TLC & -0.204 & 0.338 & 0.120 & 0.575 & 0.225 & 0.328 & 0.333 & 0.140 \\
\hline PLTs & -0.285 & 0.177 & -0.333 & 0.112 & 0.105 & 0.650 & 0.208 & 0.366 \\
\hline ALT & 0.064 & 0.768 & -0.033 & 0.880 & 0.232 & 0.312 & 0.448 & $0.042 *$ \\
\hline AST & 0.118 & 0.583 & -0.192 & 0.369 & 0.233 & 0.309 & 0.324 & 0.152 \\
\hline Alb & -0.201 & 0.346 & 0.111 & 0.607 & -0.080 & 0.729 & -0.162 & 0.484 \\
\hline Bil T & -0.096 & 0.656 & 0.044 & 0.840 & 0.128 & 0.581 & 0.166 & 0.472 \\
\hline Bil D & -0.107 & 0.619 & 0.166 & 0.437 & 0.271 & 0.235 & 0.330 & 0.144 \\
\hline PT & 0.040 & 0.854 & 0.407 & $0.048^{*}$ & 0.271 & 0.234 & 0.197 & 0.393 \\
\hline PC & -0.502 & $0.013^{*}$ & -0.282 & 0.181 & -0.192 & 0.405 & -0.122 & 0.598 \\
\hline INR & 0.232 & 0.276 & 0.327 & 0.119 & 0.149 & 0.520 & 0.146 & 0.527 \\
\hline
\end{tabular}

$\mathrm{r}=$ Pearson correlation coefficient. ${ }^{*} P<0.05$ is significant, AFP, Alfa Fetoprotein, HB, Haemoglobin, TLC, Total Leucocytic Count, PLTs, Platelets Count, ALT, Alanine Transaminase, AST, Aspartate Transaminase, Bil T, Bilirubin Total, Bil D, Bilirubin Direct, PT, Prothrombine Time, PC, Prothrombine Concentration, INR, International Normalized Ratio.

Table 5. Validity of VEGF and AFP in differentiating HCC patients from controls.

\begin{tabular}{|c|c|c|c|c|c|}
\hline- & AUC & $\mathbf{9 5 \%}$ CI & Cut-off Value & Sensitivity & Specificity \\
\hline VEGF & 1.00 & $1.000-1.000$ & $\geq 64.2$ & $100 \%$ & $100 \%$ \\
\hline AFP & 0.280 & $0.099-0.462$ & $\geq 171.5$ & $23.8 \%$ & $100 \%$ \\
\hline
\end{tabular}

AUC, Area Under Curve, CI, Confidence Interval.

Table 6. Validity of VEGF and AFP in differentiating HCV LC patients from controls.

\begin{tabular}{|c|c|c|c|c|c|}
\hline- & AUC & $\mathbf{9 5 \%}$ CI & Cut-off Value & Sensitivity & Specificity \\
\hline VEGF & 0.968 & $0.918-1.000$ & $\geq 47.2$ & $91.7 \%$ & $100 \%$ \\
\hline AFP & 0.436 & $0.242-0.631$ & $\geq 47.5$ & $41.7 \%$ & $100 \%$ \\
\hline
\end{tabular}

AUC, Area Under Curve, CI, Confidence Interval.

Table 7. Validity of VEGF and AFP in differentiating HCC patients from HCV LC patients.

\begin{tabular}{|c|c|c|c|c|c|}
\hline- & AUC & $\mathbf{9 5 \%}$ CI & Cut-off & Sensitivity & Specificity \\
\hline VEGF & 0.474 & $0.303-0.646$ & $\geq 2281$ & $29.2 \%$ & $85.7 \%$ \\
\hline AFP & 0.545 & $0.372-0.717$ & $\geq 38.1$ & $41.7 \%$ & $76.2 \%$ \\
\hline
\end{tabular}

AUC, Area Under Curve, CI, Confidence Interval.

Hepatic fibrosis progression to liver cirrhosis and associated complications as $\mathrm{HCC}$ is closely related to pathologic angiogenesis [15], where hypoxia is a common finding from early injury until the development of liver cirrhosis. The regeneration nodules, fibrous septa and vascular remodeling with sinusoidal capillarization all lead to decreased oxygen diffusion [32], which increases the VEGF transcription and protein synthesis in the liver cirrhosis [33]. This can explain the higher serum expression of VEGF and the crucial role of angiogenesis in liver cirrhosis and HCC.

AFP can enhance tumor cell proliferation, invasion and metastasis by stimulating apoptosis of immune cell, binding AFP receptors and inducing signal transduction pathway [8]. In our study, we did not find a significant difference in the serum
AFP levels in the HCC group compared to the HCV cirrhosis group or control group as we found that some of our HCC patients had low serum AFP levels and the HCV cirrhosis group had high serum AFP levels. Researchers explained the low levels of AFP in the HCC group that not all HCC tumors can secrete AFP in the serum $[34,35]$. In a large Turkish study, the serum AFP was assessed in 1773 HCC patients and $57.9 \%$ of patients were found to have low serum AFP ranging from 20-100 IU/ml, mostly detected in patients with small-sized less aggressive tumors but low levels were also detected in some large-sized tumors [36]. The elevated levels of serum AFP in our cirrhotic group were also found in the study by Tai et al., who observed elevated AFP levels in cirrhosis without HCC [37]. The elevated levels were found in patients with hepatitis 
and liver cirrhosis most properly due to increased hepatocyte turnover present with hepatic injury, inflammation or necrosis $[38,39]$.

HCC patients who have portal vein thrombosis are usually associated with poor prognosis [40]. Also, patients with cirrhosis have a high incidence of portal vein thrombosis, especially patients with child B and C [41]. In our study, the serum levels of VEGF were highly expressed in HCC patients with portal vein thrombosis, which was not observed in patients with liver cirrhosis. Similarly, other studies found a significant increase in serum VEGF in patients with $\mathrm{HCC}$ with portal vein thrombosis compared to patients without this complication [42, 43]. Li et al., postulated that VEGF can enhance portal vein thrombosis formation in $\mathrm{HCC}$ by influencing the angiogenesis process [43]. On the other hand, we did not find a significant correlation between the serum VEGF levels and the number of hepatic focal lesions in contrast to other researchers [24, 44] where VEGF accelerates vascular permeability which increases the release of malignant cells into the circulation [45].

In our study, we found that serum VEGF levels strongly correlated with serum AFP which agrees with other studies [24, $46,47]$, and this supports the prognostic value of both VEGF and AFP in HCC patients [47]. According to the relationship between VEGF and liver function tests, we did not find significant correlations between them in both the HCC group and HCV liver cirrhosis group which agrees with the results obtained by Atta et al. [24], where they postulated that VEGF expression cannot be considered as an indicator of the liver synthetic function or the inflammatory state which eliminates the possibility that inflammatory process has an impact on VEGF expression. On the contrary, Jaroszewicz et al., found positive correlations between serum VEGF and liver enzymes and hypothesized that serum VEGF expression can show the degree of hepatic function impairment in liver cirrhosis [48].

In our study, we found high sensitivity (100\%) and high specificity $(100 \%)$ for the serum VEGF in differentiating HCC patients from controls with a cut-off value of $\geq 64.2 \mathrm{pg} / \mathrm{ml}$, while we found low sensitivity $(23.8 \%)$ and high specificity $(100 \%)$ for AFP to detect HCC patients from controls. In the study by Yvamoto et al., serum VEGF was found to have $40 \%$ sensitivity and $96 \%$ specificity with $\mathrm{AUC}=0.709$ for detecting HCC patients from control and AFP showed $28 \%$ sensitivity and $99 \%$ specificity with a cut-off value of $200 \mathrm{ng} / \mathrm{ml}$ to detect HCC patients from controls [23]. Therefore, AFP is not a reliable method for screening HCC because of its low sensitivity [5]. This can elucidate the use of serum VEGF as a noninvasive serological marker for diagnosing $\mathrm{HCC}$ from healthy subjects.

Interestingly, we also found that serum VEGF showed high sensitivity (91.7\%) and high specificity (100\%) in detecting HCV LC patients from controls with a cut-off value of $\geq 47.2$ $\mathrm{pg} / \mathrm{ml}$. We also found low sensitivity and specificity to diagnose HCC from HCV LC patients, thus elucidating the crucial role of VEGF in the process of angiogenesis in both disorders and its unreliability to be used as a tumor marker for diagnosing HCC in high-risk patients of liver cirrhosis.
There were some limitations in our study: the relatively small sample size of our studied groups, patients were not in the early disease stages and it is preferable to measure these biomarkers in early stages of cirrhosis and HCC to detect their validity for early diagnosis.

\section{CONCLUSION}

Serum VEGF levels were highly expressed in both HCC and HCV LC patients which elucidates the crucial role of angiogenesis in both HCC and liver cirrhosis. Also, serum VEGF levels were highly expressed in HCC patients with portal vein thrombosis which expresses their value in prognosis. Serum VEGF level showed high sensitivity and specificity in detecting HCC patients from controls so it can be used as a reliable serological marker for diagnosing HCC patients from healthy subjects, but it cannot be used as a marker for diagnosing HCC patients from high-risk patients as $\mathrm{HCV}$ liver cirrhosis. Further studies are still needed to detect the role of VEGF in different chronic liver diseases and other reliable biomarkers for early detection of HCC from high-risk patients.

\section{ETHICS APPROVAL AND CONSENT TO PART- ICIPATE}

The research protocols were approved by the medical ethics committee of Kasr Al Ainy Medical School, Cairo University.

\section{HUMAN AND ANIMAL RIGHTS}

No animals were used in this research. All human research procedures followed were in accordance with the ethical standards of the committee responsible for human experimentation (institutional and national), and with the Helsinki Declaration of 1975, as revised in 2013.

\section{CONSENT FOR PUBLICATION}

All participants provided informed consent after the research protocols were carefully explained to them.

\section{AVAILABILITY OF DATA AND MATERIALS}

Not applicable.

\section{FUNDING}

None

\section{CONFLICT OF INTERESTS}

The authors declare no conflict of interest, financial or otherwise.

\section{ACKNOWLEDGEMENTS \\ None \\ REFERENCES}

[1] Chen JG, Zhu J, Zhang YH, Chen YS, Ding LL. Incidence trend of liver cancer: An analysis of 40 year's data from Qidong populationbased cancer registry. Zhong Guo Zhong Liu 2014; 23(8): 621-8. [Google Scholar]

[2] Jemal A, Bray F, Center MM, Ferlay J, Ward E, Forman D. Global cancer statistics. CA Cancer J Clin 2011; 61(2): 69-90. [http://dx.doi.org/10.3322/caac.20107] [PMID: 21296855]

[3] Siegel R, Naishadham D, Jemal A. Cancer statistics, 2012. CA Cancer 
J Clin 2012; 62(1): 10-29.

[http://dx.doi.org/10.3322/caac.20138] [PMID: 22237781]

[4] Llovet JM, Burroughs A, Bruix J. Hepatocellular carcinoma. Lancet 2003; 362(9399): 1907-17.

[http://dx.doi.org/10.1016/S0140-6736(03)14964-1]

[PMID: 14667750]

[5] Bruix J, Sherman M. American Association for the Study of Liver Diseases. Management of hepatocellular carcinoma: An update. Hepatology 2011; 53(3): 1020-2. [http://dx.doi.org/10.1002/hep.24199] [PMID: 21374666]

[6] Paranaguá-Vezozzo DC, Ono SK, Alvarado-Mora MV, et al. Epidemiology of HCC in Brazil: Incidence and risk factors in a tenyear cohort. Ann Hepatol 2014; 13(4): 386-93.

[http://dx.doi.org/10.1016/S1665-2681(19)30845-2] [PMID: 24927609]

[7] Mak LY, Cruz-Ramón V, Chinchilla-López P, et al. Global epidemiology, prevention, and management of hepatocellular carcinoma. Am Soc Clin Oncol Educ Book 2018; 38: 262-79. [http://dx.doi.org/10.1200/EDBK 200939] [PMID: 30231359]

[8] Wang X, Wang Q. Alpha-Fetoprotein and Hepatocellular Carcinoma Immunity. Can J Gastroenterol Hepatol 2018; 20189049252 [http://dx.doi.org/10.1155/2018/9049252] [PMID: 29805966]

[9] Bruix J, Llovet JM. Prognostic prediction and treatment strategy in hepatocellular carcinoma. Hepatology 2002; 35(3): 519-24. [http://dx.doi.org/10.1053/jhep.2002.32089] [PMID: 11870363]

[10] Abelev GI. Production of embryonal serum alpha-globulin by hepatomas: Review of experimental and clinical data. Cancer Res 1968; 28(7): 1344-50.

[PMID: 4174340]

[11] Chen L, Ho DW, Lee NP, et al. Enhanced detection of early hepatocellular carcinoma by serum SELDI-TOF proteomic signature combined with alpha-fetoprotein marker. Ann Surg Oncol 2010; 17(9): 2518-25.

[http://dx.doi.org/10.1245/s10434-010-1038-8] [PMID: 20354800]

[12] Hao K, Luk JM, Lee NP, et al. Predicting prognosis in hepatocellular carcinoma after curative surgery with common clinicopathologic parameters. BMC Cancer 2009; 9: 389 .

[http://dx.doi.org/10.1186/1471-2407-9-389] [PMID: 19886989]

[13] Toyoda H, Kumada T, Tada T, et al. Clinical utility of highly sensitive Lens culinaris agglutinin-reactive alpha-fetoprotein in hepatocellular carcinoma patients with alpha-fetoprotein $<20 \mathrm{ng} / \mathrm{mL}$. Cancer Sci 2011; 102(5): 1025-31.

[http://dx.doi.org/10.1111/j.1349-7006.2011.01875.x] [PMID: 21244578]

[14] Fujiyama S, Morishita T, Hashiguchi O, Sato T. Plasma abnormal prothrombin (des-gamma-carboxy prothrombin) as a marker of hepatocellular carcinoma. Cancer 1988; 61(8): 1621-8. [http://dx.doi.org/10.1002/1097-0142(19880415)61:8<1621::AID-CN CR2820610820>3.0.CO;2-C] [PMID: 2450634]

[15] Elpek GÖ. Angiogenesis and liver fibrosis. World J Hepatol 2015; 7(3): 377-91.

[http://dx.doi.org/10.4254/wjh.v7.i3.377] [PMID: 25848465]

[16] Mukozu T, Nagai H, Matsui D, Kanekawa T, Sumino Y. Serum VEGF as a tumor marker in patients with HCV-related liver cirrhosis and hepatocellular carcinoma. Anticancer Res 2013; 33(3): 1013-21. [PMID: 23482775]

[17] Yamaguchi R, Yano H, Nakashima Y, et al. Expression and localization of vascular endothelial growth factor receptors in human hepatocellular carcinoma and non-HCC tissues. Oncol Rep 2000; 7(4): 725-9. [PubMed]. [Google Scholar].

[http://dx.doi.org/10.3892/or.7.4.725] [PMID: 10854533]

[18] Poon RT, Lau C, Pang R, Ng KK, Yuen J, Fan ST. High serum vascular endothelial growth factor levels predict poor prognosis after radiofrequency ablation of hepatocellular carcinoma: Importance of tumor biomarker in ablative therapies. Ann Surg Oncol 2007; 14(6): 1835-45.

[http://dx.doi.org/10.1245/s10434-007-9366-z] [PMID: 17406950]

[19] Zhang L, Wang JN, Tang JM, et al. VEGF is essential for the growth and migration of human hepatocellular carcinoma cells. Mol Biol Rep 2012; 39(5): 5085-93.

[http://dx.doi.org/10.1007/s11033-011-1304-2] [PMID: 22161247]

[20] Medina J, Arroyo AG, Sánchez-Madrid F, Moreno-Otero R. Angiogenesis in chronic inflammatory liver disease. Hepatology 2004; 39: $1185-95$.

[http://dx.doi.org/10.1002/hep.20193] [PMID: 15122744]

[21] Yoshiji H, Kuriyama S, Yoshii J, et al. Vascular endothelial growth factor and receptor interaction is a prerequisite for murine hepatic fibrogenesis. Gut 2003; 52(9): 1347-54.

[http://dx.doi.org/10.1136/gut.52.9.1347] [PMID: 12912869]

[22] Llovet JM, Ducreux M, Lencioni R, Di Bisceglie AM, Galle PR, Dufour JF. European Association for the Study of the Liver European Organisation for Research and Treatment of Cancer: EASL-EORTC clinical practice guidelines: Management of hepatocellular carcinoma. J Hepatol 2012; 56(4): 908-43.

[http://dx.doi.org/10.1016/j.jhep.2011.12.001] [PMID: 22424438]

[23] Yvamoto EY, Ferreira RF, Nogueira V, et al. Influence of vascular endothelial growth factor and alpha-fetoprotein on hepatocellular carcinoma. Genet Mol Res 2015; 14(4): 17453-62.

[http://dx.doi.org/10.4238/2015.December.21.16] [PMID: 26782388]

[24] Atta MME-SA, Atta HM, Gad MA-M, et al. Clinical significance of vascular endothelial growth factor in hepatitis $\mathrm{C}$ related hepatocellular carcinoma in Egyptian patients. J Hepatocell Carcinoma 2016; 3: 19-24.

[http://dx.doi.org/10.2147/JHC.S86708] [PMID: 27574588]

[25] Sharma BK, Srinivasan R, Kapil S, et al. Angiogenic and antiangiogenic factor gene transcript level quantitation by quantitative real time PCR in patients with hepatocellular carcinoma. Mol Biol Rep 2013; 40(10): 5843-52.

[http://dx.doi.org/10.1007/s11033-013-2690-4] [PMID: 24057240]

[26] Grizzi F, Franceschini B, Hamrick C, Frezza EE, Cobos E, ChirivaInternati $\mathrm{M}$. Usefulness of cancer-testis antigens as biomarkers for the diagnosis and treatment of hepatocellular carcinoma. J Transl Med 2007; 5: 3 .

[http://dx.doi.org/10.1186/1479-5876-5-3] [PMID: 17244360]

[27] Gadelhak NA, Gadelhak SA, El-Morsi DA, Abdelaziz MM, Abbas AT, El-Emshaty HM. Prognostic significance of three hepatitis markers (p53 antibodies, vascular endothelial growth factors and alpha fetoprotein) in patients with hepatocellular carcinoma. Hepatogastroenterology 2009; 56(94-95): 1417-24. [PMID: 19950803]

[28] Uematsu S, Higashi T, Nouso K, et al. Altered expression of vascular endothelial growth factor, fibroblast growth factor-2 and endostatin in patients with hepatocellular carcinoma. J Gastroenterol Hepatol 2005; 20(4): 583-8.

[http://dx.doi.org/10.1111/j.1440-1746.2005.03726.x] [PMID: 15836707]

[29] Giatromanolaki A, Kotsiou S, Koukourakis MI, Sivridis E. Hindawi Publishing Corporation. Angiogenic factor expression in hepatic cirrhosis. Mediators Inflamm 2007; 2007: 67187. [http://dx.doi.org/10.1155/2007/67187] [PMID: 17497037]

[30] Ceauşu RA, Cîmpean AM, Gaje P, Raica M. Overexpression of VEGF and VEGFR2 in chronic hepatitis and liver cirrhosis. Research and Clinical Medicine 2016; 1: 28-32.

[31] Deli G, Jin $\mathrm{CH}$, Mu R, et al. Immunohistochemical assessment of angiogenesis in hepatocellular carcinoma and surrounding cirrhotic liver tissues. World J Gastroenterol 2005; 11(7): 960-3. [http://dx.doi.org/10.3748/wjg.v11.i7.960] [PMID: 15742396]

[32] Zhang Z, Zhang F, Lu Y, Zheng S. Update on implications and mechanisms of angiogenesis in liver fibrosis. Hepatol Res 2015; 45(2): 162-78.

[http://dx.doi.org/10.1111/hepr.12415] [PMID: 25196587]

[33] El-Assal ON, Yamanoi A, Soda Y, et al. Clinical significance of microvessel density and vascular endothelial growth factor expression in hepatocellular carcinoma and surrounding liver: Possible involvement of vascular endothelial growth factor in the angiogenesis of cirrhotic liver. Hepatology 1998; 27(6): 1554-62. [http://dx.doi.org/10.1002/hep.510270613] [PMID: 9620326]

[34] Lok AS, Sterling RK, Everhart JE, et al. HALT-C Trial Group. Desgamma-carboxy prothrombin and alpha-fetoprotein as biomarkers for the early detection of hepatocellular carcinoma. Gastroenterology 2010; 138(2): 493-502 [http://dx.doi.org/10.1053/j.gastro.2009.10.031] [PMID: 19852963]

[35] Zhang XF, Qi X, Meng B, et al. Prognosis evaluation in alphafetoprotein negative hepatocellular carcinoma after hepatectomy: Comparison of five staging systems. Eur J Surg Oncol 2010; 36(8): 718-24.

[http://dx.doi.org/10.1016/j.ejso.2010.05.022] [PMID: 20538423]

[36] Carr BI, Akkiz H, Üsküdar O, et al. HCC with low- and normal-serum alpha-fetoprotein levels. Clin Pract (Lond) 2018; 15(1): 453-64. [http://dx.doi.org/10.4172/clinical-practice.1000393] [PMID: 29576865]

[37] Tai WC, Hu TH, Wang JH, et al. Clinical implications of alphafetoprotein in chronic hepatitis C. J Formos Med Assoc 2009; 108(3): 210-8. 
[http://dx.doi.org/10.1016/S0929-6646(09)60054-1]

[PMID: 19293036]

[38] van der Veek PP, de Vos Tot Nederveen Cappel WH, Langers AM, van Hoek B. Two patients with extremely elevated tumor markers: Where is the malignancy? Gastroenterol Res Pract 2011; 2011123743 [http://dx.doi.org/10.1155/2011/123743] [PMID: 21760772]

[39] Di Bisceglie AM, Sterling RK, Chung RT, et al. HALT-C Trial Group. Serum alpha-fetoprotein levels in patients with advanced hepatitis C: Results from the HALT-C Trial. J Hepatol 2005; 43(3): 434-41. [http://dx.doi.org/10.1016/j.jhep.2005.03.019] [PMID: 16136646]

[40] Jiang JF, Lao YC, Yuan BH, et al. Treatment of hepatocellular carcinoma with portal vein tumor thrombus: Advances and challenges. Oncotarget 2017; 8(20): 33911-21.

[http://dx.doi.org/10.18632/oncotarget.15411] [PMID: 28430610]

[41] Villa E, Cammà C, Marietta $\mathrm{M}$, et al. Enoxaparin prevents portal vein thrombosis and liver decompensation in patients with advanced cirrhosis. Gastroenterology 2012; 143(5): 1253-1260.e4. [http://dx.doi.org/10.1053/j.gastro.2012.07.018] [PMID: 22819864]

[42] Kaseb AO, Hassan MM, Lin E, et al. V-CLIP: Integrating plasma vascular endothelial growth factor into a new scoring system to stratify patients with advanced hepatocellular carcinoma for clinical trials. Cancer 2011; 117(11): 2478-88.

[http://dx.doi.org/10.1002/cncr.25791] [PMID: 24048796]

[43] Li Q, Xu B, Fu L, Hao XS. Correlation of four vascular specific growth factors with carcinogenesis and portal vein tumor thrombus formation in human hepatocellular carcinoma. J Exp Clin Cancer Res 2006; 25(3): 403-9. [PMID: 17167981]
[44] Sergio A, Cristofori C, Cardin R, et al. Transcatheter arterial chemoembolization (TACE) in hepatocellular carcinoma (HCC): The role of angiogenesis and invasiveness. Am J Gastroenterol 2008; 103(4): 914-21.

[http://dx.doi.org/10.1111/j.1572-0241.2007.01712.x]

[PMID: 18177453]

[45] Sheen IS, Jeng KS, Shih SC, et al. Clinical significance of the expression of isoform 165 vascular endothelial growth factor mRNA in noncancerous liver remnants of patients with hepatocellular carcinoma. World J Gastroenterol 2005; 11(2): 187-92.

[http://dx.doi.org/10.3748/wjg.v11.i2.187] [PMID: 15633213]

[46] Guan Q, Gu J, Zhang H, Ren W, Ji W, Fan Y. Correlation between vascular endothelial growth factor levels and prognosis of hepatocellular carcinoma patients receiving radiofrequency ablation. Biotechnol Biotechnol Equip 2015; 29(1): 119-23.

[http://dx.doi.org/10.1080/13102818.2014.981776] [PMID: 26019624]

[47] Corradini SG, Morini S, Liguori F, et al. Differential vascular endothelial growth factor A protein expression between small hepatocellular carcinoma and cirrhosis correlates with serum vascular endothelial growth factor A and alpha-fetoprotein. Liver Int 2009; 29(1): 103-12.

[http://dx.doi.org/10.1111/j.1478-3231.2008.01781.x]

[PMID: 18544126]

[48] Jaroszewicz J, Januszkiewicz M, Flisiak R, Rogalska M, Kalinowska A, Wierzbicka I. Circulating vascular endothelial growth factor and its soluble receptors in patients with liver cirrhosis: Possible association with hepatic function impairment. Cytokine 2008; 44(1): 14-7. [http://dx.doi.org/10.1016/j.cyto.2008.06.002] [PMID: 18656381]

\section{(C) 2019 Sadik et al.}

This is an open access article distributed under the terms of the Creative Commons Attribution 4.0 International Public License (CC-BY 4.0), a copy of which is available at: (https://creativecommons.org/licenses/by/4.0/legalcode). This license permits unrestricted use, distribution, and reproduction in any medium, provided the original author and source are credited. 